\title{
Advanced Compressor Loss Correlations, Part I: Theoretical Aspects
}

\author{
M. T. SCHOBEIRI* \\ Turbomachinery Performance Laboratory, Texas A\&M University CS., TX 77843-3123
}

(Received 2 August 1996)

\begin{abstract}
Reliable efficiency calculation of high-subsonic and transonic compressor stages requires a detailed and accurate prediction of the flow field within these stages. Despite the tremendous progress in turbomachinery computational fluid mechanics, the compressor designer still uses different loss correlations to estimate the total pressure losses and thus the efficiency of the compressor stage. A new loss model is presented in this article. Special attention is paid to the shock and profile losses, since they contribute significantly to the total pressure loss balance, specifically for transonic compressor stages. A new shock loss model is presented that calculates the shock position and the shock total pressure losses. The available experimental data were used to establish new loss correlations that account for experimental findings.
\end{abstract}

Keywords: Compressor, transonic, subsonic, loss, correlations

\section{INTRODUCTION}

The development in the field of turbomachinery computational fluid dynamics (CFD) has reached an advanced level that allows a detailed calculation of the complex three-dimensional viscous flow through a compressor stage using Navier-Stokes codes. Recent case studies presented at the 1994 IGTI-Conference displayed the capability of different CFD methods to calculate various flow quantities in detail. However, the efficiency and loss calculations revealed a significant discrepancy between the experiment and numerical calculation. To predict the compressor stage effi- ciency accurately, the compressor designer often uses loss correlations that reflect different loss mechanisms within the compressor stage flow field. In the early fifties, Lieblein and his co-workers [1953, 1954, 1956, 1957, 1959] conducted fundamental research in compressor cascade and stage aerodynamics. Their research work, NASA-Report SP-36 [1965], is a guideline for compressor designers. Miller and Hartmann [1958], Miller et al. [1961], and Schwenk et al. [1957] initiated their fundamental research on transonic compressors, where they primarily investigated the shock losses. Gostelow et al. [1968], Gostelow [1971], Seylor and Smith [1967], Seylor and Goste-

*Corresponding author. Tel.: (409) 845-0819. 
low [1967], Gostelow and Krabacher [1967], Krabacher and Gostelow [1967a,b] focused their experimental research on single stage high Mach number compressor stages. Their comprehensive experimental research includes the performance evaluation of several rotors. Monsarrat et al. [1969] performed similar investigations on single stage high Mach number compressor stages. Koch and Smith [1976] presented a method for calculating the design point efficiency potential of a multi-stage compressor. Schobeiri [1987] investigated the individual loss mechanisms that occur in an advanced compressor stage. He developed a new shock loss model, introduced a modified diffusion factor, and re-evaluated the significant experimental data published by NASA (see previous references). Recent investigations by König et al. [1994a,b] investigate the loss and deviation angles for transonic bladings.

This paper focuses on three issues: (1) A new modified diffusion factor that describes the blade loading for the rectilinear and annular cascades, as well as for the entire compressor stage. This new diffusion factor, which includes the compressibility effects, allow's the loss parameters to be systematically correlated with the diffusion factor. (2) A new shock loss model is presented that overcomes the weaknesses of the existing loss models described by Levine [1957], Balzer [1970] and Swan [1961]. (3) The existing published data are re-evaluated and detailed correlations are presented.

\section{TOTAL PRESSURE LOSSES IN AN ADVANCED COMPRESSOR}

The total pressure losses encountered in an advanced compressor stage are: (1a) The blade primary losses generated by the wall shear stress, which is proportional to the local velocity deformation. The primary losses are restricted to the middle of the blade surface area and thus not affected by the secondary vortices generated by the secondary flow on the blade hub and tip. (1b) The trailing edge mixing losses are due to the thickness of the trailing edge and the boundary layer thicknesses on the suction and pressure surfaces that causes wake defect, mixing, and thus additional entropy increase. From an experimental point of view, these two losses are not separable, since the total pressure measurements occur at a certain distance downstream of the trailing edge plane and inherently include the wake total pressure defect. The combination of these two losses is frequently called a profile loss. (2) Shock losses are encountered in compressor stages with high transonic to supersonic inlet flow conditions. Based on an angle incidence and the shock position, these losses may generate considerable entropy increase that results in a significant deterioration of the stage efficiency. The shock losses are approximately of the same order of magnitude as the profile losses. (3) Secondary losses due to the end wall boundary layer development and blade-wall clearances. (4) Secondary flow losses are also present for compressor blades with shrouds. A comprehensive treatment of losses is found in Schobeiri [1987].

\section{Profile Losses}

Lieblein and Roudebusch [1956] derived the expression for profile loss coefficient as a function of cascade geometry, flow angles, and the boundary layer parameters shown in Eq. (1):

$$
\zeta_{P}=\sigma\left(\frac{\theta}{c}\right)\left(\frac{\sin \beta_{1}}{\sin \beta_{2}}\right)^{2}\left(\frac{1+H_{32}}{\left(1-\frac{\theta}{c} \sigma H_{12}\right)^{3}}\right)
$$

with the form factor $H_{32}=f\left(H_{12}\right)$. Among the boundary layer parameters in Eq. (1), the momentum thickness $\theta$ is of primary importance. It gives a direct relationship between the separation point and the freestream velocity gradient (or pressure gradient) shown in the following von Kàrmàn integral equation for incompressible flow:

$$
\frac{\tau_{0}}{\rho V^{2}}=\frac{d \theta}{d x}+\left(2+H_{12}\right) \frac{\theta}{V} \frac{d V}{d x}
$$

with $\tau_{0}$ as the wall shear stress and $H_{12}$ the form parameter. For a highly loaded compressor blade, the 
velocity distribution may separate. Consequently, the wall shear stress vanishes and Eq. (2) may reduce to:

$$
\frac{d \theta}{d x}=-\left(2+H_{12}\right) \frac{\theta}{V} \frac{d V}{d x}
$$

Equation (3). shows a direct relation between the blade velocity gradient and the momentum thickness. Appropriate differences can approximate the above differentials. As an appropriate measure for the velocity gradient, Lieblein et al. [3] introduced the equivalent diffusion factor:

$$
D_{e q}=\frac{V_{\max }}{V_{2}}=\frac{V_{1}}{V_{2}} \frac{V_{\max }}{V_{1}}
$$

with $V_{\max }$ as the maximum velocity on the suction surface. This velocity ratio, which changes by changing the flow deflection given by the velocity triangle, properly reflects the blade loading situation. However, it requires the knowledge of the maximum velocity at different flow deflections, which is not always given. From a compressor designer point of view, relating the blade loading to the actual velocity triangle is most appropriate.

\section{New Diffusion Factor}

We introduce the dimensionless parameter $\eta=V / V_{l}$, $\xi=x / b$ and approximate the dimensionless velocity distribution $\eta$ by:

$$
\eta=\sum_{0}^{N} a_{n} \xi^{n}=a_{0}+a_{1} \xi+a_{2} \xi^{2}+\ldots \ldots \ldots . . . a_{n} \xi^{n}
$$

The Taylor expansion in the near of $\xi_{\max }$ results in:

$$
\eta=\eta_{\max }+\frac{d \eta}{d \xi} \Delta \xi+\frac{1}{2} \frac{d^{2} \eta}{d \xi^{2}} \Delta \xi^{2}+\ldots \ldots . .
$$

with $\Delta \xi=\xi-\xi_{\text {max }}$. Neglecting the higher order terms, Eq. (6) can reduce to

$$
\eta=\eta_{\max }+\left(\frac{d \eta}{d \xi}\right)_{\xi_{\max }}\left(\xi-\xi_{\max }\right)
$$

The velocity slope is found from Eq. (5):

$$
\left(\frac{d \eta}{d \xi}\right)_{\xi_{\max }}=a_{1}+2 a_{2} \xi_{\max }
$$

Incorporating Eq. (8) into Eq. (7) results in:

$$
\eta=\eta_{\max }+C_{1} \xi+C_{2}
$$

with the constants: $C_{1}=a_{1}+2 a_{2} \xi_{\max }$ and $C_{2}=$ $-C_{1} \xi_{\max }$. The tangential component of the force acting on the blade (see Fig. 1) is calculated by integrating the pressure distribution along the blade suction and pressure surfaces using the Bernoulli equation:

$$
T=T_{S}-T_{P}=\frac{1}{2} \rho \int_{0}^{b}\left(V_{S}^{2}-V_{P}^{2}\right) d x
$$

Since only the contribution of the suction surface is considered for estimating the diffusion factor, the second term in the integrand may be set equal to zero. Incorporating Eq. (9) into Eq. (10) results in:

$$
\begin{gathered}
\frac{T}{\frac{1}{2} \rho V_{1}^{2} b}=\eta_{\max }^{2}+\left(C_{1}+2 C_{2}\right) \eta_{\max }+ \\
\frac{1}{3} C_{1}^{2}+C_{1} C_{2}+C_{2}^{2}
\end{gathered}
$$

The force component $T$ can also be calculated using the momentum equation in the tangential direction:

$$
T=s \rho V_{a}\left(V_{t 1}-V_{t 2}\right)
$$

with $s$ and $\rho$ as the blade spacing and the flow density, $V_{a}$ and $V_{t}$ as the axial and tangential velocity components. Inserting the velocity components defined in Fig. (1) into Eq. (12), it becomes:

$$
\frac{T}{\frac{1}{2} \rho V_{1}^{2} b}=2 \frac{s}{b} \sin ^{2} \beta_{1}\left(\cot \beta_{1}-\cot \beta_{2}\right)
$$



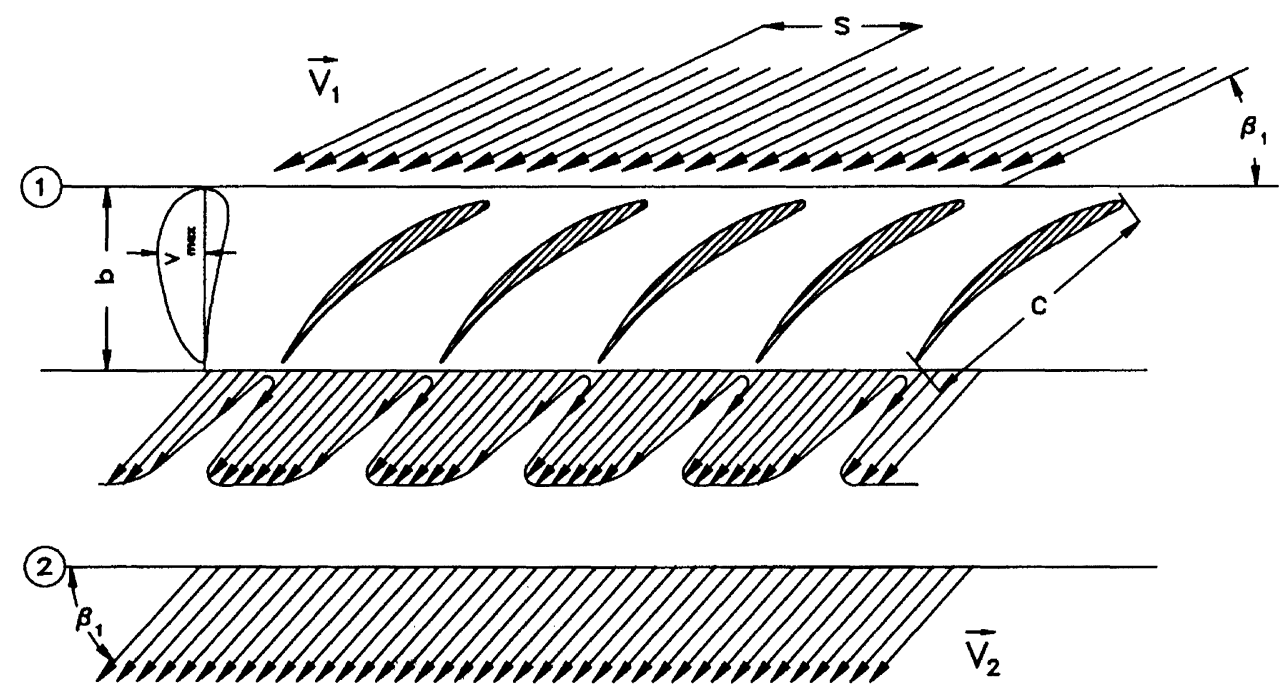

FIGURE 1 Schematic representation of a compressor cascade flow.

Equating Eq. (11) and (13) results in the following relationship:

$$
\eta_{\max }^{2}+D_{1} \eta_{\max }+D_{3}=0
$$

with the coefficients $D_{i}$ as:

$$
\begin{aligned}
& D_{1}=C_{1}+2 C_{2} \\
& D_{2}=C_{1} C_{2}+C_{2}^{2}+\frac{1}{3} C_{1}^{2} \\
& D_{3}=D_{2}-\frac{2 s}{b} \sin ^{2} \beta_{1}\left(\cot \beta_{1}-\cot \beta_{2}\right)
\end{aligned}
$$

The solution of Eq. (14) after neglecting the higher order terms in $D_{3}$ yields:

$$
\begin{aligned}
\eta_{\max }=\frac{V_{\max }}{V_{1}}=K_{1} & {\left[\frac{\sin ^{2} \beta_{1}}{\sigma}\left(\cot \beta_{1}-\cot \beta_{2}\right)\right]+K_{2} } \\
& =K_{1} G+K_{2}
\end{aligned}
$$

Equation (15) exhibits a special case of Eq. (14) and gives an explicit relationship between the maximum velocity $V_{\max }$ and the cascade circulation function $G=\sin ^{2} \beta_{1} / \sigma\left(\cot \beta_{1}-\cot \beta_{2}\right)$ in the bracket. Using the NACA-65(A10) series and the circular arc blade C.4, for the optimum flow condition denoted by $(*)$, the constants in Eq. (15) are experimentally determined by Lieblein [1959]:

$$
\begin{gathered}
\left(\frac{V_{\max }}{V_{1}}\right)^{*}=K_{1} G^{*}+K_{2}=1.12+ \\
0.6 \frac{\sin ^{2} \beta_{1}}{\sigma}\left(\cot \beta_{1}-\cot \beta_{2}\right)
\end{gathered}
$$

Equation (14) is generally valid for any arbitrary inlet flow angle including the off-design incidence angles. However, the compressor designer prefers to relate the off-design $\eta_{\max }$ to the design point condition. Lieblein [1975] introduced an empirical correlation for $V_{\max } / V_{l}$ for positive angles of attack as a function of the incidence angle $i=\beta-\beta^{*}$.

$$
\left(\frac{V_{\max }}{V_{1}}\right)=1.12+0.61 G^{*}+a\left(\beta_{1}-\beta_{1}^{*}\right)^{1.42}
$$

where $\mathrm{a}=0.0117$ for the NACA 65(A10) and $\mathrm{a}=$ 0.0070 for the C. 4 circular arc blades. Eq. (17) accurately estimates the maximum velocity ratio for a positive incidence. However, Eq. (17) cannot be used for negative incidence angles $i=\beta-\beta^{*}$ because of 
the rational exponent of the argument $\beta-\beta^{*}$. Introducing the angle $\beta=\beta^{*}+i$ into Eq. (14) eliminates this deficiency and after some rearranging we obtain:

$$
\eta_{\max }=\eta_{\max }^{*}+\sum_{1}^{N} a_{n}\left(\beta_{1}-\beta_{1}^{*}\right)^{n}
$$

Neglecting terms with $n>2$, Eq. (18) becomes

$$
\left(\frac{V_{\max }}{V_{1}}\right)=\left(\frac{V_{\max }}{V_{1}}\right)^{*}+a_{1}\left(\beta_{1}-\beta_{1}^{*}\right)+a_{2}\left(\beta_{1}-\beta_{1}^{*}\right)^{2}
$$

Re-evaluating the experimental results by Lieblein [1957] leads to $a_{1}=0.746$ and $a_{2}=0.65$. Equation (19) enables the calculation of the velocity ratio and thus the diffusion factor for any off-stall operation range. Figure (2) compares the results of Eq. (19) with the experiments, where the velocity ratio is plotted against the circulation function $\mathrm{G}$ with the incidence angle $i=\beta-\beta^{*}$ as a parameter. Compared

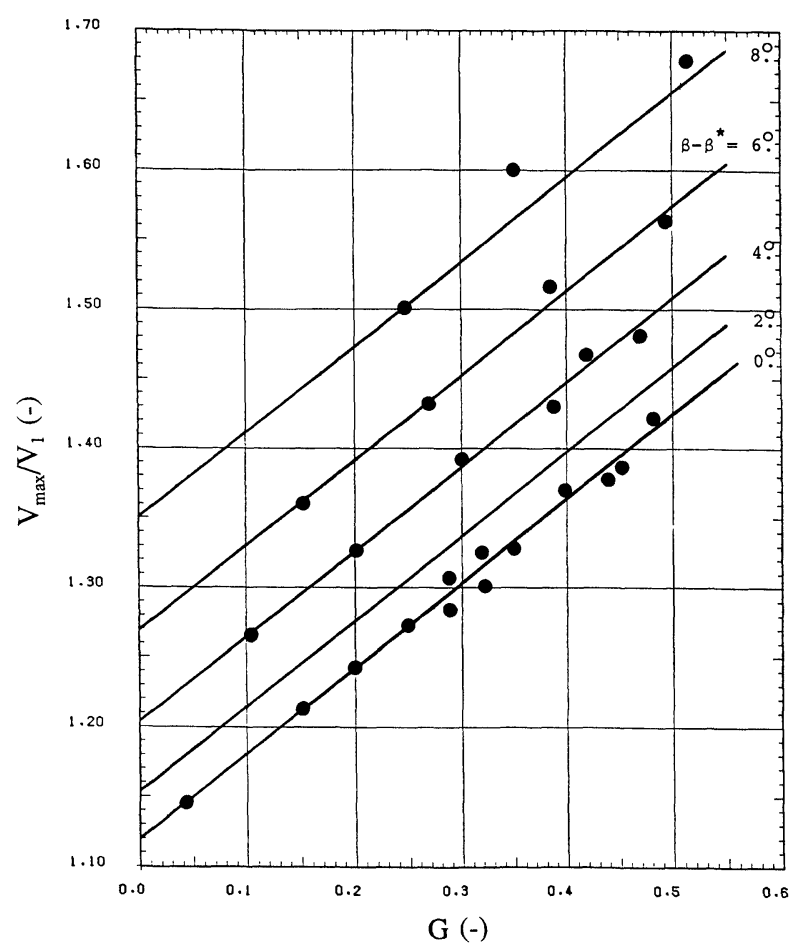

FIGURE 2 Velocity ratio as a function of $\mathrm{G}$ with the incidence angle as parameter. with Lieblein's correlation Eq. (17), the new correlation Eq. (19) yields more accurate results. This statement is also true for Fig. (3), where the maximum velocity ratio is plotted versus the incidence angle with the lift coefficient $C_{10}$ as parameter.

\section{Generalized Maximum Velocity Ratio for Cascade, Stage}

Lieblein's correlations were further extended in previous section for the maximum velocity ratio and their experimental verifications were based exclusively on the two-dimensional incompressible cascade flow situation. Significant effects such as compressibility and three-dimensionality were not considered. Furthermore, changes of axial velocity component and streamline curvature, which are always present in a modern compressor, were ignored. Finally, the effect of rotational motion on circulation was disregarded. This section includes the above

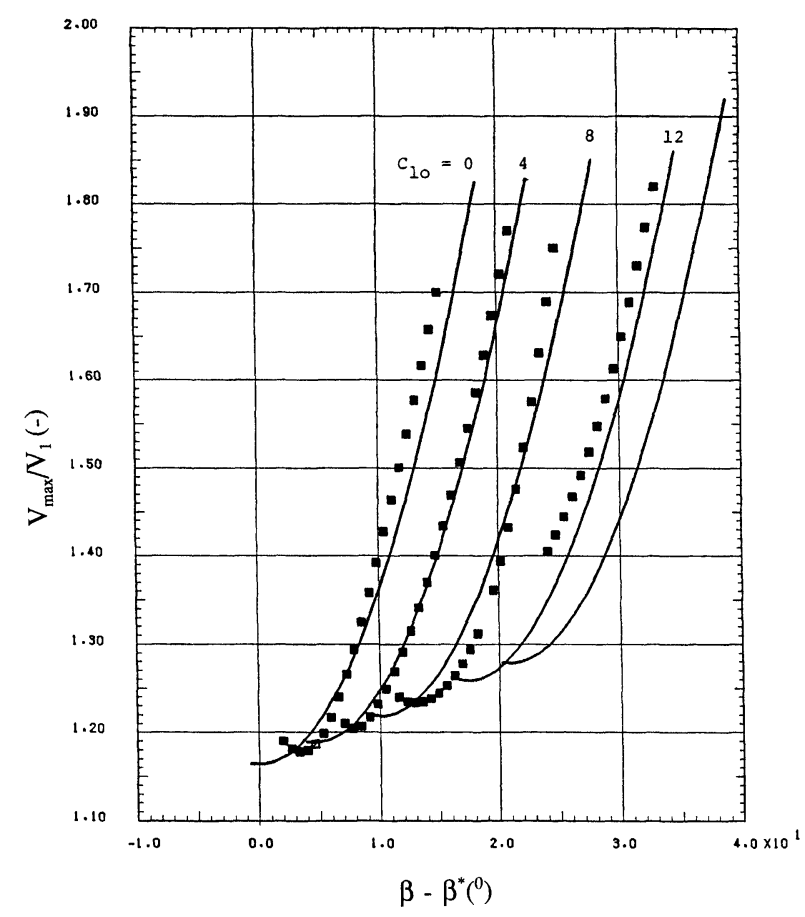

FIGURE 3 Velocity ratio as a function of incidence angle with the lift coefficient as parameter. 
mentioned effects in the maximum velocity ratio by employing a generalized circulation concept that leads to a modified diffusion factor. Starting from the Kutta-Joukowsky's lift equation (lift force/unit span) with $\rho_{\infty}, V_{\infty}$ as the freestream density, velocity, and $\Gamma$ as the circulation:

$$
\vec{A}=\rho_{\infty} \vec{V}_{\infty} x \vec{\Gamma}
$$

Using the definition in Figs. (4) and (5) for linear and annular cascades, the circulation is expressed as:

$\Gamma=\oint \vec{V} \cdot \overrightarrow{d s} \equiv \Gamma_{12}+\Gamma_{23}+\Gamma_{34}+\Gamma_{41}=V_{t 1} s_{1}-V_{t 2} s_{2}$

where $V_{t 1}$ and $V_{t 2}$ represent the tangential velocity components at the inlet and exit and $\Gamma_{23}=-\Gamma_{41}$. For a rectilinear cascade with constant height or a stator cascade with a constant radius cylinder streamlines, the spacings are equal at the inlet and exit $s_{1}=\mathrm{s}_{2}=$
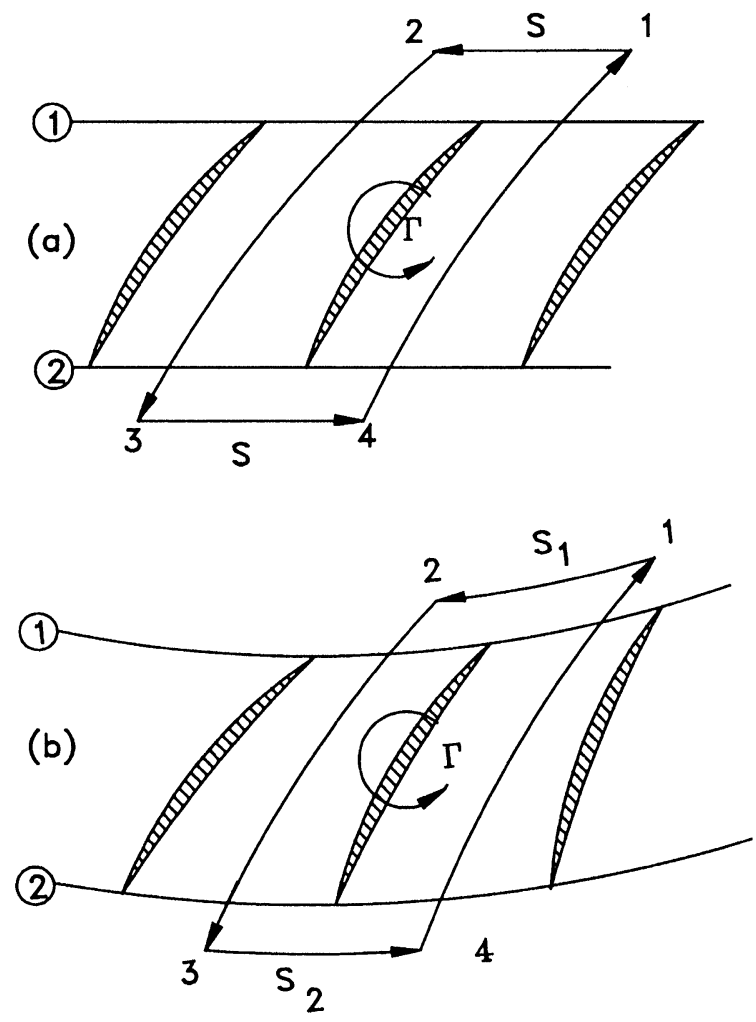

FIGURE $4 \mathrm{a}, \mathrm{b}$ Circulation of a linear and an axisymmetric cascade.

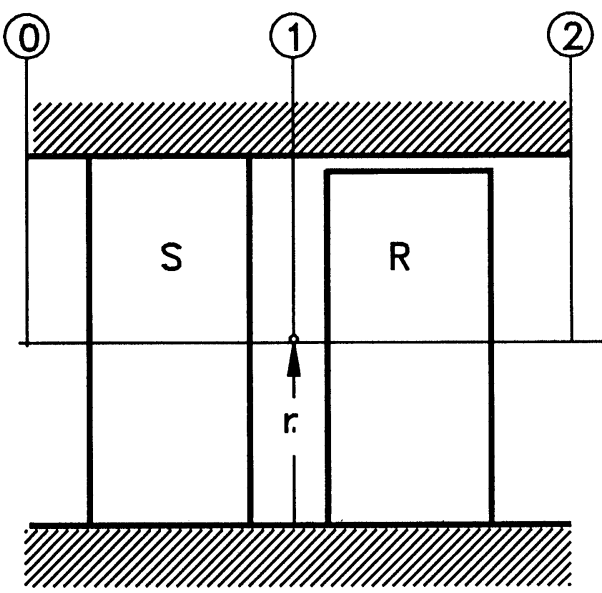

(a)

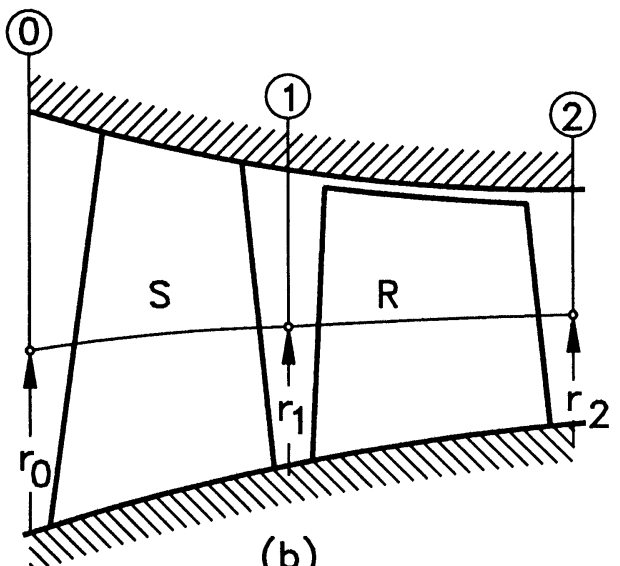

(b)

FIGURE 5a, b Cross section of two compressor stages with a constant and a variable mean diameter.

s. For a stator cascade with conical streamline (Figs. $4 \mathrm{~b}, 5 \mathrm{~b}$ ), different spacings at the inlet and exit are present that relate to each other by the radius of the streamline curvature, $s_{1}=\Delta \vartheta r_{1}, s_{2}=\Delta \vartheta r_{2}$. Using the following velocity ratios:

$$
\phi=\frac{V_{a 2}}{U_{2}}, \quad \nu=\frac{U_{1}}{U_{2}}=\frac{r_{1}}{r_{2}}, \quad \mu=\frac{V_{a 1}}{V_{a 2}}=\frac{W_{a 1}}{W_{a 2}}
$$

and defining the specific circulation function $\gamma$, we obtain the following relations for the linear cascade $\gamma_{C}$, stator $\gamma_{S}$ and rotor $\gamma_{R}$ 


$$
\gamma_{C}=\frac{A_{C}}{\rho_{\infty} V_{\infty} V_{a 1} s}=\left(V_{t 1}-V_{t 2}\right) \frac{1}{V_{a 1}}=\cot \beta_{1}-\cot \beta_{2}
$$

$$
\begin{gathered}
\gamma_{S}=\frac{A_{s}}{\rho_{\infty} V_{\infty} V_{a 1} s_{1}}=\left(V_{t 1}-V_{t 2} \frac{r_{2}}{r_{1}}\right) \frac{1}{V_{a 1}}= \\
\cot \beta_{1}-\frac{1}{\nu \mu} \cot \beta_{2} \\
\gamma_{R}=-\frac{U_{1}}{V_{a 1}}+\frac{W_{t 1}}{V_{a 1}}+\frac{r_{2}}{r_{1}} \frac{U_{2}}{V_{a 1}}-\frac{r_{2}}{r_{1}} \frac{W_{t 2}}{V_{z 1}}= \\
\frac{1}{\nu \phi \mu}\left(1-\nu^{2}\right)+\cot \beta_{1}-\frac{1}{\nu \mu} \cot \beta_{2}
\end{gathered}
$$$$
\left(\frac{V_{\max }}{V_{1}}\right)_{C, S, R}^{*}=b_{1}+b_{2} G_{C, S, R}^{*}
$$

Correspondingly, we obtain the off-design maximum velocity ratio by using Eq. (19):

$$
\begin{gathered}
\left(\frac{V_{\max }}{V_{1}}\right)_{C, S, R}=a_{1}\left(\beta_{1}-\beta_{1}^{*}\right)+a_{2}\left(\beta_{1}-\beta_{1}^{*}\right)^{2}+b_{1} \\
+b_{2} G_{C, S, R}^{*}
\end{gathered}
$$

In Eqs. (26) and (27), the individual quantities denoted by the subscripts $\mathrm{C}, \mathrm{S}$, and $\mathrm{R}$ pertain to cascade, stator and rotor, respectively. The Lieblein's equivalent diffusion factor is then:

Equation (24) exhibits a generalized relation for the specific circulation function. As seen, to calculate circulation the absolute velocity components $V_{t 1}$ and $V_{t 2}$ are utilized and refer to the absolute circulation rather than the relative one. Special cases such as the linear cascade, stator with cylindrical streamlines, and stator with axisymmetric streamlines can follow immediately by setting:

case 1:

$\mathrm{u}=0, \phi=\infty, \mu=1, v=1$ (linear cascade, cylindrical stator)

case 2

$\mathrm{u}=0, \quad \phi=\infty, \mu \neq 1, v \neq 1$ (axisymmetric stator) case 3

$\mathrm{u} \neq 0, \quad \phi \neq \infty, \mu \neq 1, v=1$ (cylindrical rotor) case 4

$\mathrm{u} \neq 0, \quad \phi \neq \infty, \mu \neq 1, \nu \neq 1$ (axisymmetric rotor)

Using the most general case (Eq. 24), we obtain the circulation function for the rotor as:

$$
\begin{gathered}
G_{R}=\frac{\sin ^{2} \beta_{1}}{\sigma} \gamma_{R}=\frac{\sin ^{2} \beta_{1}}{\sigma} \mathrm{x} \\
\left(\frac{1}{\mu \nu \phi}\left(1-\nu^{2}\right)+\cot \beta_{1}-\frac{1}{\mu \nu} \cot \beta_{2}\right)
\end{gathered}
$$

With Eqs. (22-24) the maximum velocity ratio at the optimum point for cascade $(\mathrm{C})$, stator $(\mathrm{S})$, and rotor (R) are calculated from:

$$
\begin{aligned}
D_{e q}=\frac{V_{\max }}{V_{2}} & =\mu \frac{\sin \beta_{2}}{\sin \beta_{1}}\left(\frac{V_{\max }}{V_{1}}\right)=\mu \frac{\sin \beta_{2}}{\sin \beta_{1}}\left[a_{1}\left(\beta_{1}-\beta_{1}^{*}\right)\right. \\
& \left.+a_{2}\left(\beta_{1}-\beta_{1}^{*}\right)^{2}+b_{1}+b_{2} G_{C, S, R}^{*}\right]
\end{aligned}
$$

\section{Compressibility Effect}

To consider the effect of compressibility on the maximum velocity ratio and thus on the diffusion factor, we modify the specific circulation function for the simplest case, namely a linear cascade, by introducing the inlet density $\rho_{l}$ :

$$
\gamma_{C_{C}}=\frac{A_{C}}{\rho_{1} V_{\infty} V_{a 1} s}=\frac{\rho_{\infty}}{\rho_{1}}\left(V_{t 1}-V_{t 2}\right) \frac{1}{V_{a 1}}
$$

The second subscript $\mathrm{c}$ refers to compressible flow. The freestream density $\rho_{\infty}$ can be expressed in terms of the density at the inlet and a finite increase $\rho_{\infty}=\rho_{l}$ $+\Delta \rho$. Outside the boundary layer we assume a potential flow that is not influenced by small perturbations. With this assumption, the Euler equation combined with the speed of sound may be applied:

$$
V d V=-C^{2} \frac{d \rho}{\rho}
$$


with $\mathrm{C}$ as the speed of sound. For small changes, the flow quantities can be related to the quantities at the inlet:

$$
\begin{aligned}
& V=V_{1}+\Delta V ; \quad C=C_{1}+\Delta C \\
& \rho=\rho_{1}+\Delta \rho ; \quad d \rho \cong \Delta \rho
\end{aligned}
$$

We introduce the above relations into Eq. (30) and approximate the differentials by differences and neglect the higher order terms. After some rearranging we obtain the density changes by:

$$
\frac{\Delta \rho}{\rho_{1}}=-M_{1}^{2}\left(\frac{V_{2}}{V_{1}}\right)\left(\frac{V_{2}}{V_{1}}-1\right)
$$

Introducing Eq. (31) into the relation $\rho_{\infty}=\rho_{1}+\Delta \rho$ results in:

$$
\frac{\rho_{\infty}}{\rho_{1}}=\left[1-M_{1}^{2}\left(\frac{\sin \beta_{1}}{\sin \beta_{2}}\right)\left(\frac{\sin \beta_{1}}{\sin \beta_{2}}-1\right)\right]
$$

Implementing Eq. (32) into Eq. (29) obtains the specific circulation functions for linear cascade and stators with cylindrical streamlines:

$$
\begin{gathered}
\gamma_{C_{C}}=\left[1-M_{1}^{2}\left(\frac{\sin \beta_{1}}{\sin \beta_{2}}\right)\left(\frac{\sin \beta_{1}}{\sin \beta_{2}}-1\right)\right]\left[\cot \beta_{1}\right. \\
\left.-\cot \beta_{2}\right]
\end{gathered}
$$

The expression in the above bracket reflects the Mach number effect on the specific circulation function. Using the same principle, the generalized circulation function for the rotor is obtained by:

$$
\begin{gathered}
\gamma_{R_{C}}=\left[1-M_{1}^{2}\left(\frac{\sin \beta_{1}}{\sin \beta_{2}} \frac{1}{\mu}\right)\left(\frac{\sin \beta_{1}}{\sin \beta_{2}} \frac{1}{\mu}-1\right)\right] \\
{\left[\frac{1}{\mu \nu \phi}\left(1-v^{2}\right)+\cot \beta_{1}-\frac{1}{\mu \nu} \cot \beta_{2}\right]}
\end{gathered}
$$

This equation allows calculation of the specific circulation function for cases 1 to 4 . As seen from Eqs. (33) and (34) and comparing them with Eqs. (23) and
(24), the specific circulation of compressible and incompressible flows are related to each other by the density ratio and thus the Mach number. Considering the simplest case, namely the linear cascade described by Eq. (34), because of the compression process with $\beta_{2}<\beta_{1}$, the bracket representing the compressibility effect is always greater than unity. With Eq. (34) and the condition for case 1 to case 4, the circulation function for cascade, stator, and rotor with compressible flow are:

$$
\left(G_{C, S, R}\right)_{C}=\frac{\sin ^{2} \beta_{1}}{\sigma}\left(\gamma_{C, S, R}\right)_{C}
$$

The subscripts C, S and R refer to the cases discussed above. Using Eq. (35) for optimum conditions, the velocity ratio for compressible flow is obtained from:

$$
\begin{gathered}
\left(\frac{V_{\max }}{V_{1}}\right)_{(G, S, R) C}=a_{1}\left(\beta_{1}-\beta_{1}^{*}\right)+a_{2}\left(\beta_{1}-\beta_{1}^{*}\right)^{2}+b_{1} \\
+b_{2} G_{(G, S, R) C}^{*}
\end{gathered}
$$

Introducing Eq. (36) into the relationship for the equivalent diffusion factor for the rotor as a generalized case, reads:

$$
\begin{gathered}
D_{e q}=\left\{a_{1}\left(\beta_{1}-\beta_{1}^{*}\right)+a_{2}\left(\beta_{1}-\beta_{1}^{*}\right)^{2}+b_{1}\right. \\
+b_{2} \frac{\sin ^{2} \beta_{1}}{\sigma}\left[\frac{1}{\mu \nu \phi}\left(1-\nu^{2}\right)+\cot \beta_{1}-\frac{1}{\mu \nu} \cot \beta_{2}\right] x \\
\left.x\left[1-\frac{1}{\mu} \frac{\sin \beta_{1}^{*}}{\sin \beta_{2}} M_{1}^{2}\left(\frac{1}{\mu} \frac{\sin \beta_{1}^{*}}{\sin \beta_{2}}-1\right)\right]\right\} \frac{\sin \beta_{2}}{\sin \beta_{1}} \mu
\end{gathered}
$$

The angles used in the above equations correspond to those defined in Figs. (1) and (6). Equations (36) and (37) show the direct relationship between the maximum velocity ratio and the specific circulation function. Equation (37) inherently includes the compress- 
ibility effect and the actual and optimum flow angles. An alternative diffusion factor, which was first proposed by Smith [1995], is:

$$
D=1-\frac{W_{2}}{W_{1}}+\frac{1}{\sigma} \frac{r_{2} V_{t 2}-r_{1} V_{t 1}}{\left(r_{1}+r_{2}\right) W_{1}}
$$

This relation has been accepted and widely used by compressor aerodynamicists. It includes the effect of the rotation in its third term. Using the angle definition in Fig. (6) and the dimensionless parameters previously defined, the rearrangement of Eq. (38) results in:

$$
\begin{gathered}
D=1-\frac{1}{\mu} \frac{\sin \beta_{1}}{\sin \beta_{2}}+\frac{\nu \sin ^{2} \beta_{1}}{\sigma(\nu+1)} \mathrm{x} \\
{\left[\frac{1}{\mu \nu \phi}\left(1-\nu^{2}\right)-\cot \beta_{1}+\frac{1}{\mu \nu} \cot \beta_{2}\right]}
\end{gathered}
$$
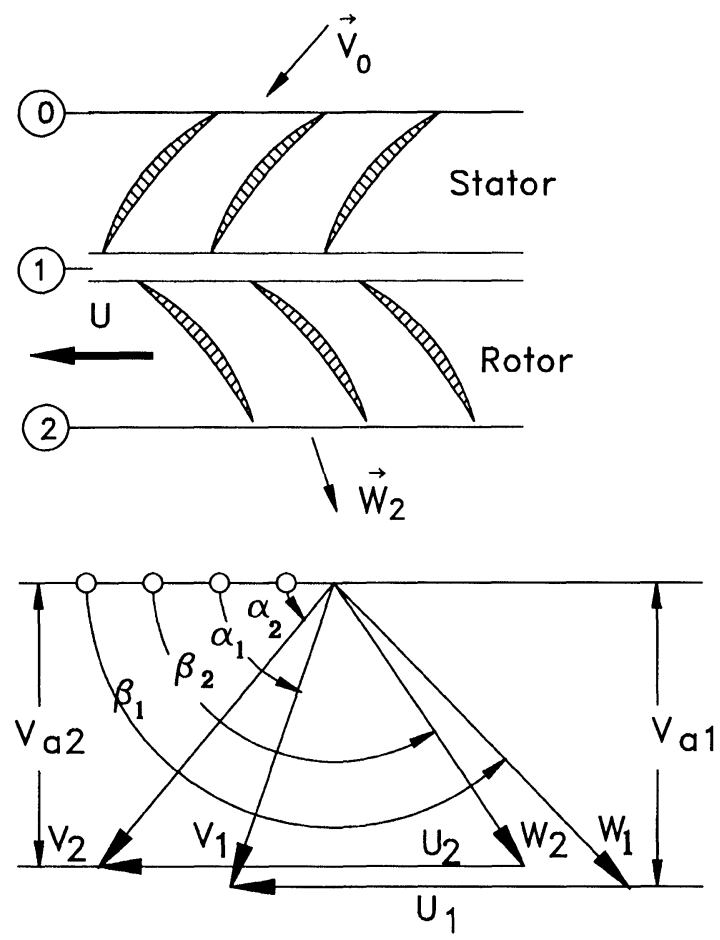

FIGURE 6 Velocity triangle, angle definition.
The crucial part of this equation is the expression in the bracket, which is identical to the specific circulation function in Eqs. (34) and (37). Introducing the compressibility effect results in a modified version of Eq. (39):

$$
\begin{gathered}
D_{m}=1-\frac{1}{\mu} \frac{\sin \beta_{1}}{\sin \beta_{2}}+\frac{\nu \sin ^{2} \beta_{1}}{\sigma(\nu+1)} \mathrm{x} \\
{\left[\frac{1}{\mu \nu \phi}\left(1-\nu^{2}\right)-\cot \beta_{1}+\frac{1}{\mu \nu} \cot \beta_{2}\right] x} \\
x\left[1-\frac{1}{\mu} \frac{\sin \beta_{1}}{\sin \beta_{2}} M_{1}^{2}\left(\frac{1}{\mu} \frac{\sin \beta_{1}}{\sin \beta_{2}}-1\right)\right]
\end{gathered}
$$

The diffusion factors previously discussed are used to establish correlations for the individual losses as well as the total losses.

\section{SHOCK LOSSES, NEW CORRELATION}

Several papers have discussed experimental and theoretical shock loss investigations. As indicated previously, Miller and Hartmann [1958], Miller et al. [1961], and Schwenk et al. [1957] initiated their fundamental research on transonic compressors where they investigated shock losses. Schwenk et al. [1957] considered a normal shock in the entrance region of the cascade using a Prandtl-Meyer expansion. Levine [1957], Balzer [1970], and Swan [1961] made efforts to calculate shock losses by estimating the shock position. Their proposed methods, particularly, Levine's [1957] and Swan's [1961] found their application in compressor design. Similar to Schwenk [1957], the methods by Levine, Balzer, and Swan include the assumption of a normal shock. While Levine and Swan considered the acceleration on the suction surface by using the continuity and Prandtl-Meyer expansion, Balzer disregarded the expansion completely and used the continuity requirement. The deficiencies in the existing methods can be summarized as: a) They cannot accurately calculate the shock position, which is a prerequisite for accurately predicting the shock losses. b) The Mach number calculated by the 
Prandtl-Meyer expansion on the suction surface does not represent the shock Mach number along the channel width. Swan partially corrected this deficiency by building an average Mach number. c) The description of the physical process is not complete: the PrandtlMeyer expansion combined with the continuity requirement is not sufficient to describe the physics. The above deficiencies gave impetus to generate the following new shock loss model. For the development of this model we assume the passage shock as an oblique shock, whose position changes according to the operating point and may include normal shock as a special case. Furthermore, we assume that the blading has a sufficiently sharp leading edge, where the shocks are attached at least at the design point with no detached bow waves expected. Figure (7) shows the shock situation with the inlet flow angle $\beta_{l}$, the metal angle $\beta_{t}$ (camber angle), and the incidence angle $i$. To determine the shock position we use the continuity equation, the Prandtl-Meyer expansion, and the momentum equation. For the control volume in Fig. (7), the continuity requirement for a uniform flow is:

$$
\rho_{1} V_{1} S_{1} \sin \beta_{1}=\rho_{s} V_{s} S_{s} \cos \delta \frac{h_{s}}{h_{1}}
$$

with $h_{1}$ and $h_{s}$ as the height of the stream tube at the inlet and at the shock position. Using the gas dynamics relationships, Eq. (41) is written as:

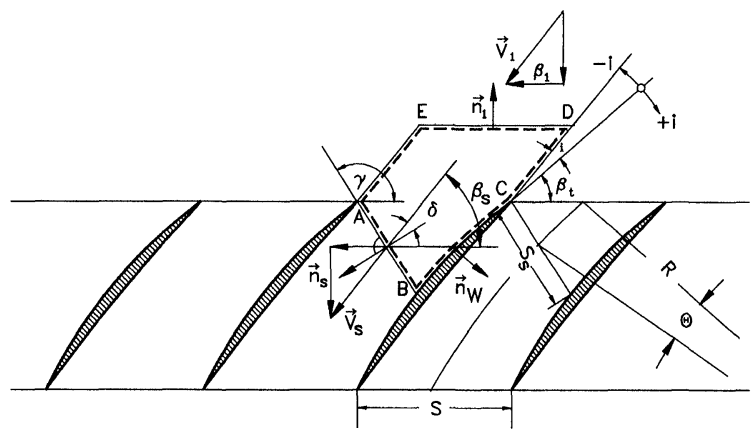

FIGURE 7 Shock position and angle definition, $\mathrm{n}_{\mathrm{l}}, \mathrm{n}_{\mathrm{s}}, \mathrm{n}_{\mathrm{w}}$ are normal unit vectors at the inlet, shock location and the wall.

$$
\frac{h_{1}}{h_{s}} \frac{S_{1} \sin \beta_{1}}{S_{s} \cos \delta}=\frac{\rho_{s}}{\rho_{1}} \frac{V_{s}}{V_{1}}=\frac{M_{s}}{M_{1}}\left(\frac{1+\frac{\kappa-1}{2} M_{1}^{2}}{1+\frac{\kappa-1}{2} M_{s}^{2}}\right)^{\frac{1}{2} \frac{\kappa+1}{\kappa-1}}
$$

with the geometric relation:

$$
\delta=\frac{\pi}{2}+\beta_{s}-\gamma
$$

The incidence and expansion angle are coupled by:

$$
i=\theta-v_{s}+v_{1}
$$

where $v$ is determined from the Prandtl-Meyer expansion law:

$$
\begin{gathered}
v=\left(\frac{\kappa+1}{\kappa-1}\right)^{\frac{1}{2}} \tan ^{-1}\left[\frac{\kappa-1}{\kappa+1}\left(M^{2}-1\right)\right]^{\frac{1}{2}}- \\
\tan ^{-1}\left(M^{2}-1\right)^{\frac{1}{2}}
\end{gathered}
$$

The momentum equation in tangential (circumferential) direction is given by:

$$
\begin{gathered}
\int_{S_{1}} V_{1} \cos \beta_{1} d \dot{m}_{1}-\int_{S_{S}} V_{S} \cos \beta_{S} d \dot{m}_{S}+ \\
\int_{S_{S}}-p_{S} \cos \left(\beta_{S}-\delta\right) d S_{S}+\int_{S_{V}}-p_{W} \cos \alpha_{W} d S_{W}=0
\end{gathered}
$$

As Fig. (7) shows, because of the cascade periodicity, the pressure at point $\mathrm{A}$ is identical to the pressure at point C. Furthermore, point B on the suction surface represents the common end point for both distances $\mathrm{AB}$ and $\mathrm{CB}$. This means that the pressure distributions along $\mathrm{AB}$ and $\mathrm{CB}$ have exactly the same beginning and ending values, but may have different distributions between the points $\mathrm{AB}$ and $\mathrm{CB}$. Assuming that differences of the pressure integrals along the shock front $\mathrm{AB}$ and the blade contour portion $\mathrm{CB}$ are 
approximately equal, their projections in circumferential direction may cancel each other and lead to:

$$
\frac{V_{1}}{V_{s}}=\frac{\cos \beta_{s}}{\cos \beta_{1}}=\frac{M_{1}}{M_{s}}\left(\frac{1+\frac{\kappa-1}{2} M_{s}^{2}}{1+\frac{\kappa-1}{2} M_{1}^{2}}\right)^{\frac{1}{2}}
$$

Finally, we arrive at a geometric closure condition that uses the mean streamline, which is assumed to be identical to the mean camber line of the blade with the radius $R$.

$$
R\left[+\cos \beta_{t}-\cos \left(\beta_{t}+\theta\right)\right]=\frac{S_{s}}{2} \sin \gamma
$$

and

$$
R\left[-\sin \beta_{t}+\sin \left(\beta_{t}+\theta\right)\right]=\frac{S_{s}}{2} \cos \gamma+\frac{S_{1}}{2}
$$

The shock angle is determined from:

$$
\tan \gamma=\frac{\cos \beta_{t}-\cos \left(\beta_{t}+\theta\right)}{-\sin \beta_{t}+\sin \left(\beta_{t}+\theta\right)-\frac{1}{2} \frac{S_{1}}{R}}
$$

Considering the above procedure, the continuity equation yields:

$$
\begin{gathered}
\frac{h_{1}}{h_{s}} \frac{\sin \left(\beta_{t}+i\right) \sin \gamma}{2 \frac{R}{S_{1}}\left[\cos \beta_{t}-\cos \left(\beta_{t}+\theta\right)\right] \sin \left(\gamma-\beta_{s}\right)} \\
=\frac{M_{s}}{M_{1}}\left(\frac{1+\frac{\kappa-1}{2} M_{1}^{2}}{1+\frac{\kappa-1}{2} M_{s}^{2}}\right)^{\frac{1}{2} \frac{\kappa+1}{\kappa-1}} \mathrm{x}
\end{gathered}
$$

With Eqs. (43), (44), (47), and (51) we have a system of four equations that easily calculates the four unknowns, namely: $\delta, \beta_{s}, \gamma$, and $M_{s}$. The shock loss is:

$$
\begin{gathered}
\zeta_{S}=\frac{P_{b}-P_{a}}{P_{b}}=1-\left[\frac{(\kappa+1) M_{s}^{2} \cos ^{2} \delta}{2+(\kappa-1) M_{s}^{2} \cos ^{2} \delta}\right]^{\frac{\kappa}{\kappa-1}} \\
{\left[1+\frac{2 \kappa}{\kappa+1}\left(M_{s}^{2} \cos ^{2} \delta-1\right)\right]^{\frac{-1}{\kappa-1}}}
\end{gathered}
$$

where $P_{b}$ and $P_{a}$ represent the total pressure before and after the shock. For $\beta_{t}=30^{\circ}$ and the incidence angle $i=0^{\circ}$, the above equation system is used to calculate the shock Mach number, the expansion angle $\theta$, the shock position $\gamma$, the total pressure ratio, and the shock losses.

Figure (8) shows the shock Mach number as a function of spacing ratio $S / R$ with the inlet Mach number $M_{l}$ as the parameter. This figure shows that increasing the spacing ratio causes the shock Mach number to continuously increase and approach an asymptotic value. These results are similar to those presented by Levine [1957]. However, the values are different because of the simplifications by Levine. Keeping the inlet Mach number constant, the increase of spacing ratio leads to higher expansion angle $\theta$ as shown in Fig. (9). However, increasing the inlet Mach number at a constant spacing ratio $S / R$ leads to a smaller expansion angle. The same tendency can be read from the charts by Levine. For an inlet Mach number $M_{I}=1.2$ and $S / R=0.5$, the Levine's method gives an expansion angle $\theta=8^{\circ}$, while the method presented in this paper calculates $\theta=9.5^{\circ}$. As indicated previously, this difference is due to the simplified assumptions by Levine. Figure (10) shows the shock angle $\gamma$ as a function of spacing ratio $S / R$. This figure shows the significant effect of the inlet Mach number on the shock position. Finally, Fig. (11) shows the total pressure ratio $\mathrm{P}_{\mathrm{a}} / \mathrm{P}_{\mathrm{b}}$ as a function of spacing ratio $S / R$ with inlet Mach number as parameter. As shown in Fig. 11, reducing the spacing ratio $S / R<1$. causes for inlet Mach numbers $\mathrm{M}_{1}>1.4$ substantial reduction in total pressure ratio. For $\mathrm{M}_{1}<$ 1.4 this tendency is reversed, resulting in higher total pressure ratios. 


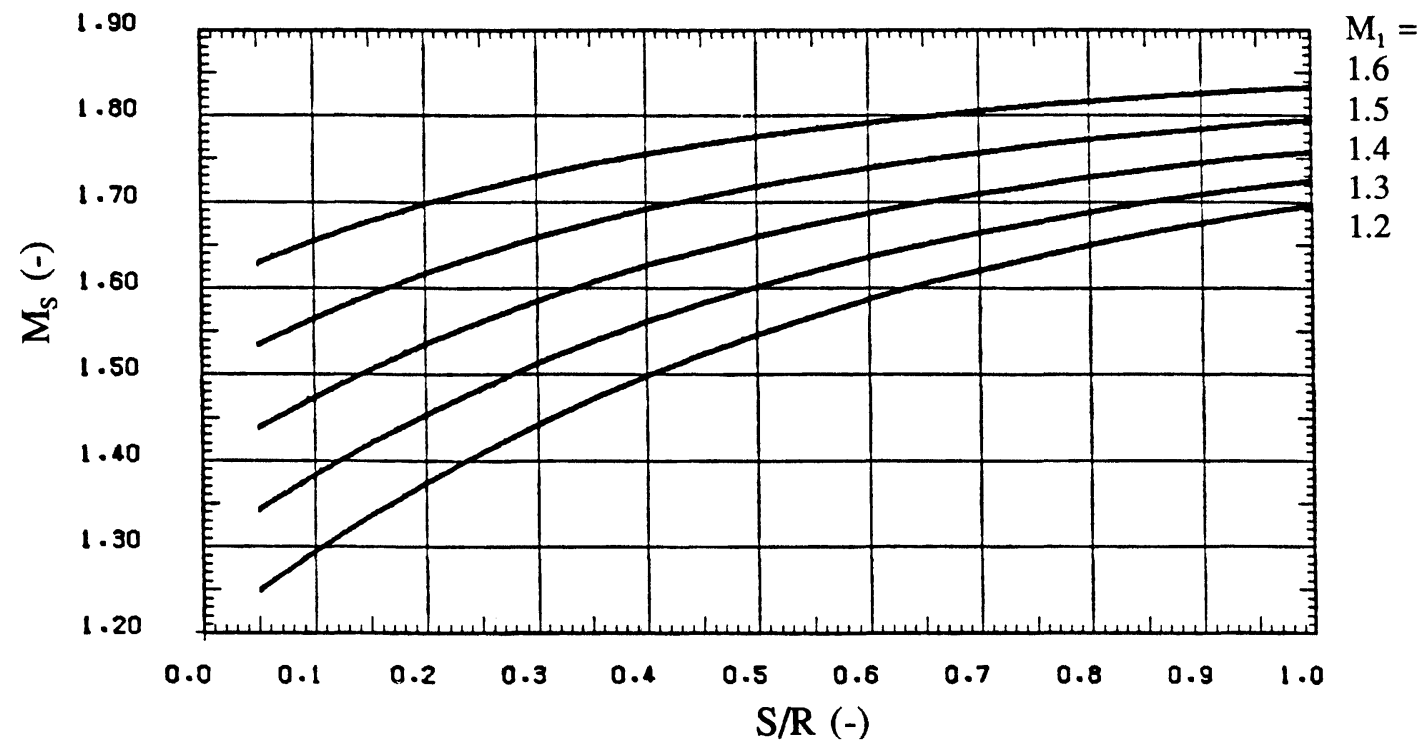

FIGURE 8 Shock Mach number as a function of the spacing ratio $S / R$ with the inlet Mach number $M_{1}$ as parameter and the incidence angle $\mathrm{i}=0^{\circ}$.

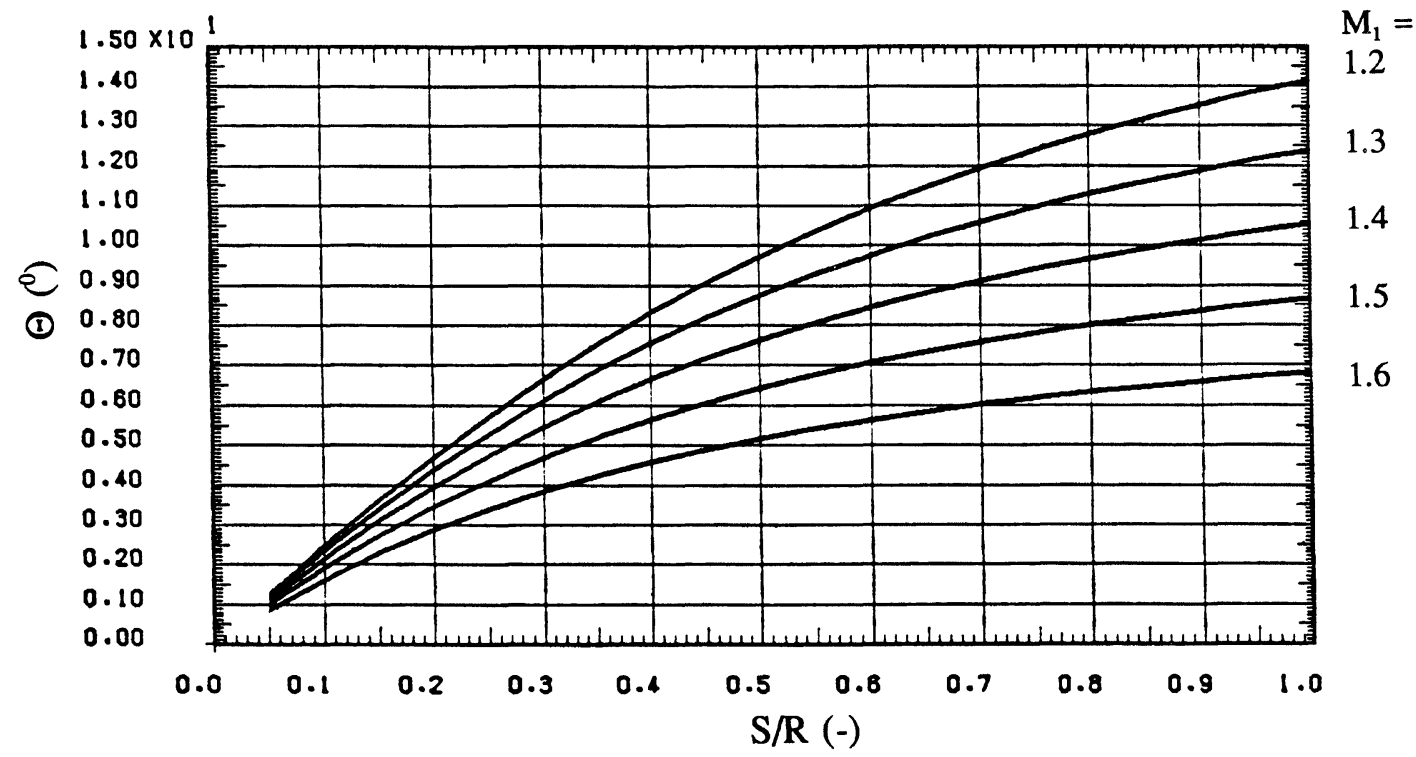

FIGURE 9 Expansion angle $\theta$ as a function of $\mathrm{S} / \mathrm{R}$ with inlet Mach number $\mathrm{M}_{1}$ as a parameter and the incidence angle $\mathrm{i}=0^{\circ}$.

\section{CONCLUSION}

The first part of this paper discussed the basic essential theoretical aspects for generating the loss correlations for advanced compressor stages. It focused on two issues: (1) A new modified diffusion factor was introduced that describes the blade loading for the rectilinear and annular cascades as well as for the entire compressor stage. This new diffusion factor, which includes the compressibility effects, allows the loss parameters to be correlated with the diffusion factor in a more systematic manner. (2) A new shock 


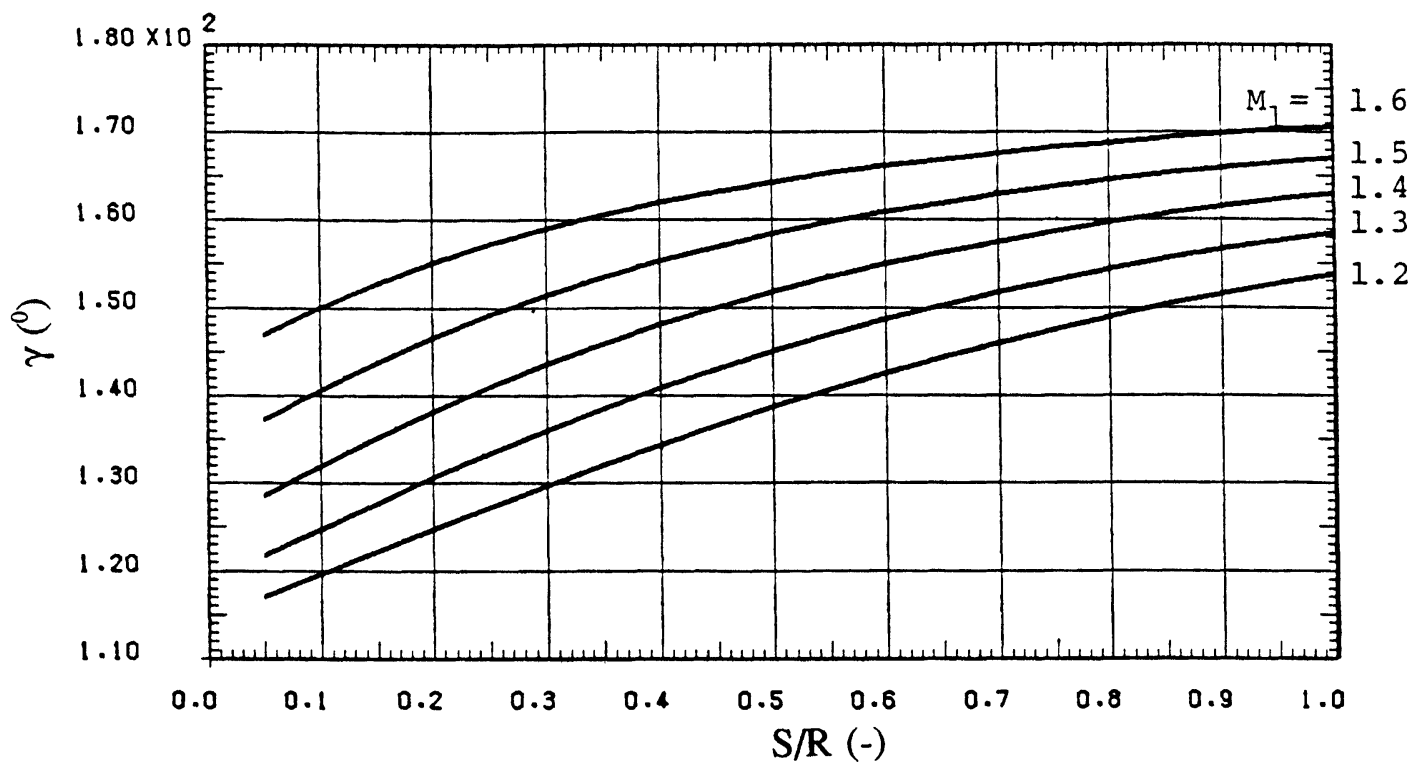

FIGURE 10 Shock position angle as a function of spacing ratio S/R with inlet Mach number as a parameter.

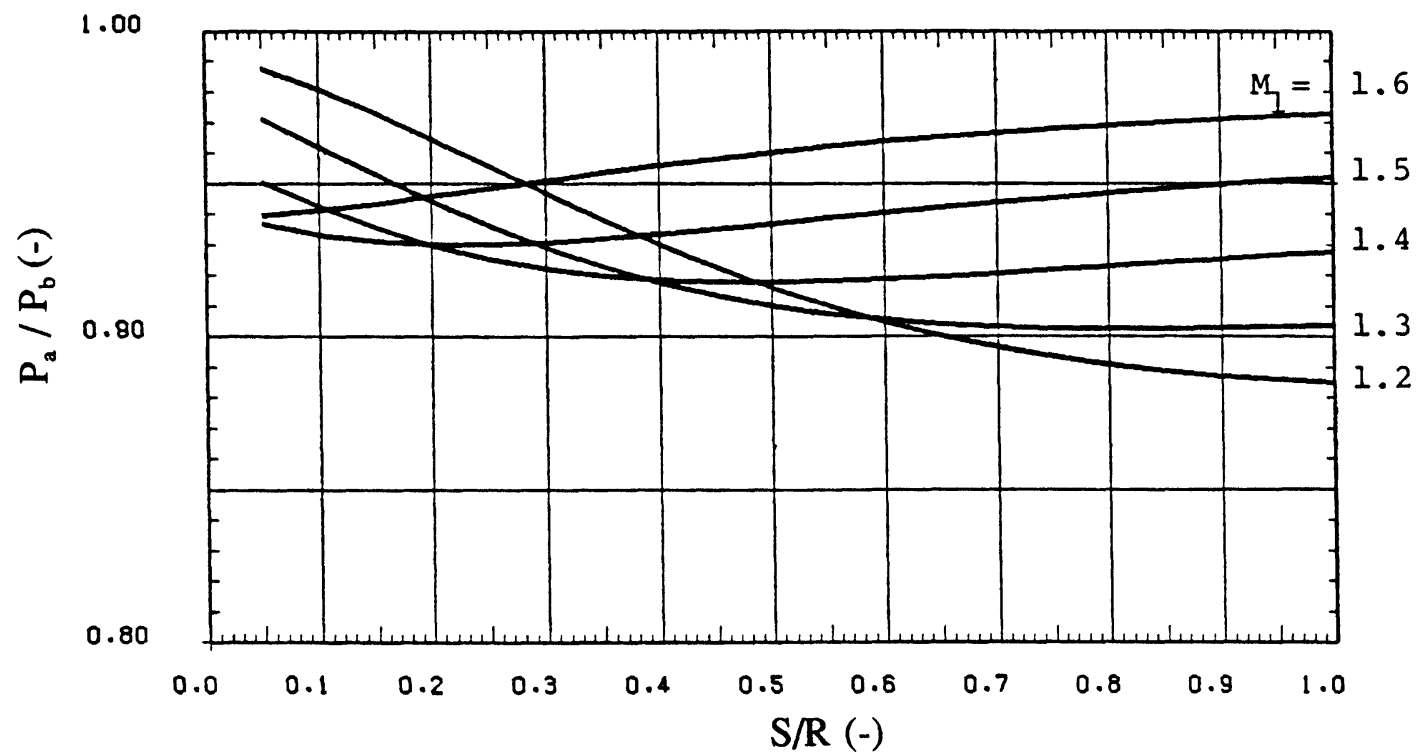

FIGURE 11 Total pressure ratio as a function of the spacing ratio with the inlet Mach number as parameter and the incidence angle $\mathrm{i}=$ $0^{\circ} . \mathrm{P}_{\mathrm{a}}, \mathrm{P}_{\mathrm{b}}=$ pressure after and before the shock.

loss model was presented that overcomes the weaknesses of the existing loss models. It accurately calculates the expansion angle, the shock position, and the shock losses. The second part of the paper reevaluated the existing published data and presented detailed correlations. 


\section{NOMENCLATURE}

$\overrightarrow{\mathrm{A}}$ force vector

$b \quad$ blade axial chord

$c \quad$ blade chord length

$C \quad$ speed of sound

$\mathrm{C}_{\mathrm{i}} \quad$ constants

$D_{e} \quad$ equivalent diffusion factor

$D_{m} \quad$ modified diffusion factor

$F \quad$ auxiliary function

G circulation function, $G=\sin ^{2} \beta_{1} / \sigma\left(\cot \beta_{1}-\cot \beta_{2}\right)$

$H_{12}$ form factor, $H_{12}=\delta / \theta$

$h$ height

$i \quad$ incidence angle

$M \quad$ Mach number

$R \quad$ radius of the mean flow path (Fig. 7)

$r_{i} \quad$ radius of stage stream surface

$S \quad$ spacing

$t \quad$ Thickness

$T$ tangential force component

$\vec{U}, \vec{V}, \vec{W}$ rotational, absolute, and relative velocity vectors

$\alpha, \beta \quad$ flow angles

$\delta \quad$ angle between the shock velocity vector and the normal unit vector

$\Delta \vartheta \quad$ segment angle

$\gamma \quad$ specific circulation function, shock angle

$\Gamma \quad$ circulation

$\xi \quad$ distance ratio $\xi=x / b$

$\zeta \quad$ loss coefficient

$\eta \quad$ velocity ratio

$\mu, \nu, \phi$ velocity ratios

$\Theta \quad$ boundary layer momentum thickness, shock expansion angle

$\sigma \quad$ cascade solidity $\sigma=\mathrm{c} / \mathrm{s}$

$\tau_{0} \quad$ wall sear stress

\section{SUB- AND SUPERSCRIPTS}

$a, t$ axial, tangential

c compressible

max maximum

$P, S$ pressure, suction surface
$C$, Cascade, stator, rotor

$S, R$

$s \quad$ Shock

* minimum loss

$\infty \quad$ freestream

\section{References}

Balzer, R. L., (1970) A method for predicting compressor cascade total pressure losses when the inlet relative Mach number is greater than unity, ASME Paper 70-GT-57.

Gostelow, J. P., Krabacher, K. W., Smith, L. H., (1968) Performance comparisons of the high Mach number compressor rotor blading NASA Washington, NASA CR-1256.

Gostelow, J. P., (1971) Design performance evaluation of four transonic compressor rotors, ASME Transactions, Journal for Engineering and Power, Vol. 93, No. 1, pp. 34-41.

Gostelow, J. P., Krabacher, K. W., (1967) Single stage experimental evaluation of high Mach number compressor rotor blading, Part III, Performance of rotor 2E. NASA CR-54583.

Krabacher, K. W., Gostelow, J. P., (1967) Single stage experimental evaluation of high Mach number compressor rotor blading, Part IV, Performance of rotor 2D. NASA CR-54584.

Krabacher, K. W., Gostelow, J. P., (1967) Single stage experimental evaluation of high Mach number compressor rotor blading, Part V, Performance of Rotor 2B. NASA CR-54585.

König, W. M., Hennecke, D. K., Fottner, L., (1994) Improved Blade Profile Loss and Deviation Angle Models for Advanced Transonic Compressor Bladings: Part I-A Model For Subsonic Flow, ASME Paper, No. 94-GT-335.

König, W. M., Hennecke, D. K., Fottner, L., (1994) Improved Blade profile Loss and deviation angle Models for Advanced Transonic Compressor Bladings: Part I-A Model For Supersonic Flow, ASME Paper, No. 94-GT-335.

Koch, C. C., Smith, L. H. (1976) Loss sources and magnitudes in axial-flow compressors, ASME Transactions, Journal for Engineering and Power, January 5, Vol. 98, No. 3, pp. 411-424.

Levine, Ph. (1957) Two-dimensional inlet conditions for a supersonic compressor with curved blades, Journal of Applied Mechanics, Vol. 24, No. 2, pp. 164-169.

Lieblein, S. (1954) Review of high performance axial flow compressor blade element theory, NACA RME 53L22.

Lieblein, S., Roudebush, W. H. (1956) Theoretical loss relations for low speed two dimensional cascade flow NACA Technical Note 3662.

Lieblein, S., Schwenk, F., Broderick, R. L. (1953) Diffusions factor for estimating losses and limiting blade loadings in axial flow compressor blade elements, NACA RME53D01.

Lieblein, S. (1957) Analysis of experimental low-speed loss and stall characteristics of two-dimensional compressor blade cascades, NACA RM E57A28.

Lieblein, S. (1959) Loss and stall analysis of compressor cascades, ASME Transactions, Journal of Basic Engineering, pp. 387400.

Miller, G. R., Hartmann, M. J. (1958) Experimental shock configuration and shock losses in a transonic compressor rotor at design point NACA RM E58A14b

Miller, G. R., Lewis, G. W., Hartmann, M. J. (1961) Shock losses in transonic compressor blade rows ASME Transactions Journal for Engineering and Power, pp. 235-241. 
Monsarrat, N. T., Keenan, M. J., Tramm, P. C. (1967) Design report, Single stage evaluation of high Mach number compressor stages, NASA CR-72562 PWA-3546.

NASA SP-36, NASA Report, 1965.

Schobeiri, M. T. (1978) Verlustkorrelationen für transsonische Kompressoren, BBC-Studie, TN-78/20.

Schwenk, F. C., Lewis, G. W., Hartmann, M. J. (1957) A preliminary analysis of the magnitude of shock losses in transonic compressors NACA RM \#57A30.

Seylor, D. R., Smith, L. H. (1967) Single stage experimental evaluation of high Mach number compressor rotor blading, Parti I, Design of rotor blading, NASA CR-54581, GE R66fpd321P.
Seylor, D. R., Gostelow, J. P. (1967) Single stage experimental evaluation of high Mach number compressor rotor blading, Part II, Performance of rotor 1B. NASA CR-54582, GE R67fpd236. Smith, L. H. (1995) Private communication with the author and the GE-Design Information Memorandum 1954: A Note on The NACA Diffusion Factor

Swan, W. C. (1961) A practical method of predicting transonic compressor performance, ASME Transactions, Journal for Engineering and Power, Vol. 83, pp. 322-330. 


\section{ait \\ ENERGY MATERIALS}

M A N E Y publishing

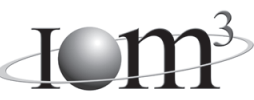

\section{Materials Science \& Engineering for Energy Systems}

Maney Publishing on behalf of the Institute of Materials, Minerals and Mining

The Institute of Materials, Minerals \& Mining

Economic and environmental factors are creating ever greater pressures for the efficient generation, transmission and use of energy. Materials developments are crucial to progress in all these areas: to innovation in design; to extending lifetime and maintenance intervals; and to successful operation in more demanding environments. Drawing together the broad community with interests in these areas, Energy Materials addresses materials needs in future energy generation, transmission, utilisation, conservation and storage. The journal covers thermal generation and gas turbines; renewable power (wind, wave, tidal, hydro, solar and geothermal); fuel cells (low and high temperature); materials issues relevant to biomass and biotechnology; nuclear power generation (fission and fusion); hydrogen generation and storage in the context of the 'hydrogen economy'; and the transmission and storage of the energy produced.

As well as publishing high-quality peer-reviewed research, Energy Materials promotes discussion of issues common to all sectors, through commissioned reviews and commentaries. The journal includes coverage of energy economics and policy, and broader social issues, since the political and legislative context influence research and investment decisions.

\section{CALL FOR PAPERS}

Contributions to the journal should be submitted online at http://ema.edmgr.com

To view the Notes for Contributors please visit: www.maney.co.uk/journals/notes/ema

Upon publication in 2006, this journal will be available via the Ingenta Connect journals service. To view free sample content online visit: www.ingentaconnect.com/content/maney

For further information please contact:

Maney Publishing UK

Tel: +44 (0)113 2497481 Fax: +44 (0)1132486983 Email: subscriptions@maney.co.uk

or

Maney Publishing North America

Tel (toll free): 8662975154 Fax: 6173546875 Email: maney@maneyusa.com

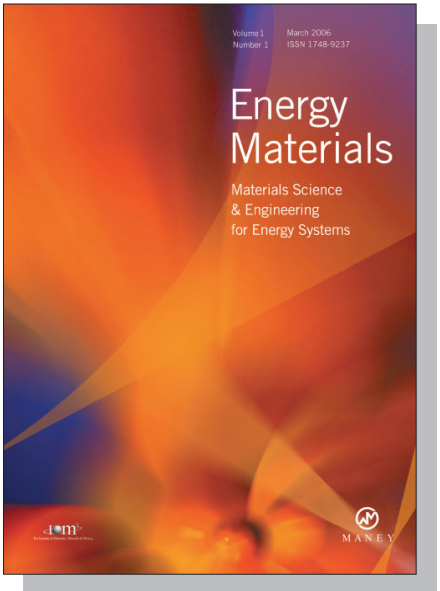

EDITORS

Dr Fujio Abe

NIMS, Japan

Dr John Hald, IPL-MPT, Technical University of Denmark, Denmark

Dr R Viswanathan, EPRI, USA

\section{SUBSCRIPTION INFORMATION}

Volume 1 (2006), 4 issues per year

Print ISSN: 1748-9237 Online ISSN: 1748-9245

Individual rate: $£ 76.00 / U S \$ 141.00$

Institutional rate: $£ 235.00 /$ US $\$ 435.00$

Online-only institutional rate: $£ 199.00 / U S \$ 367.00$

For special $\mathrm{IOM}^{3}$ member rates please email

subscriptions@maney.co.uk

\section{For further information or to subscribe online please visit www.maney.co.uk}



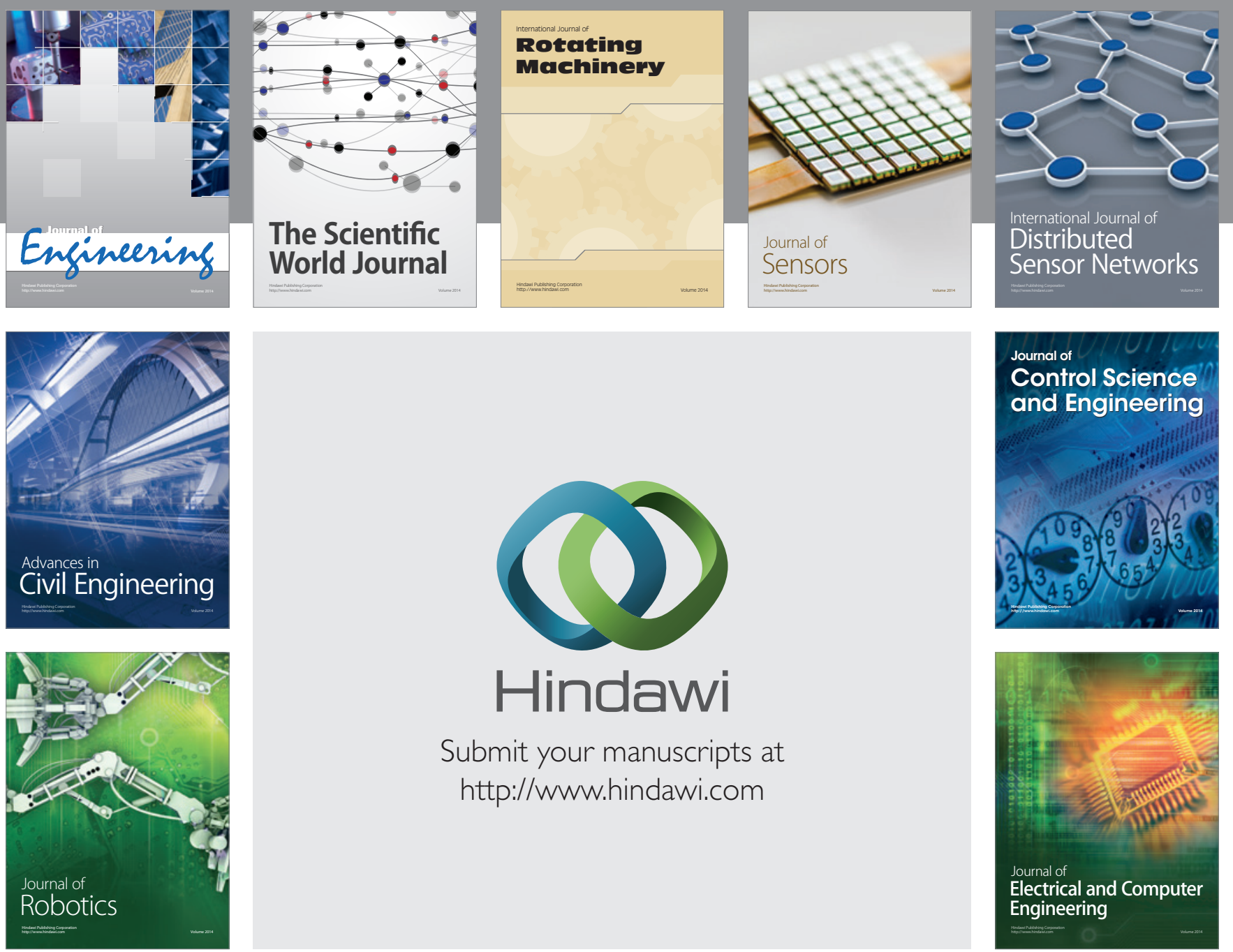

Submit your manuscripts at

http://www.hindawi.com
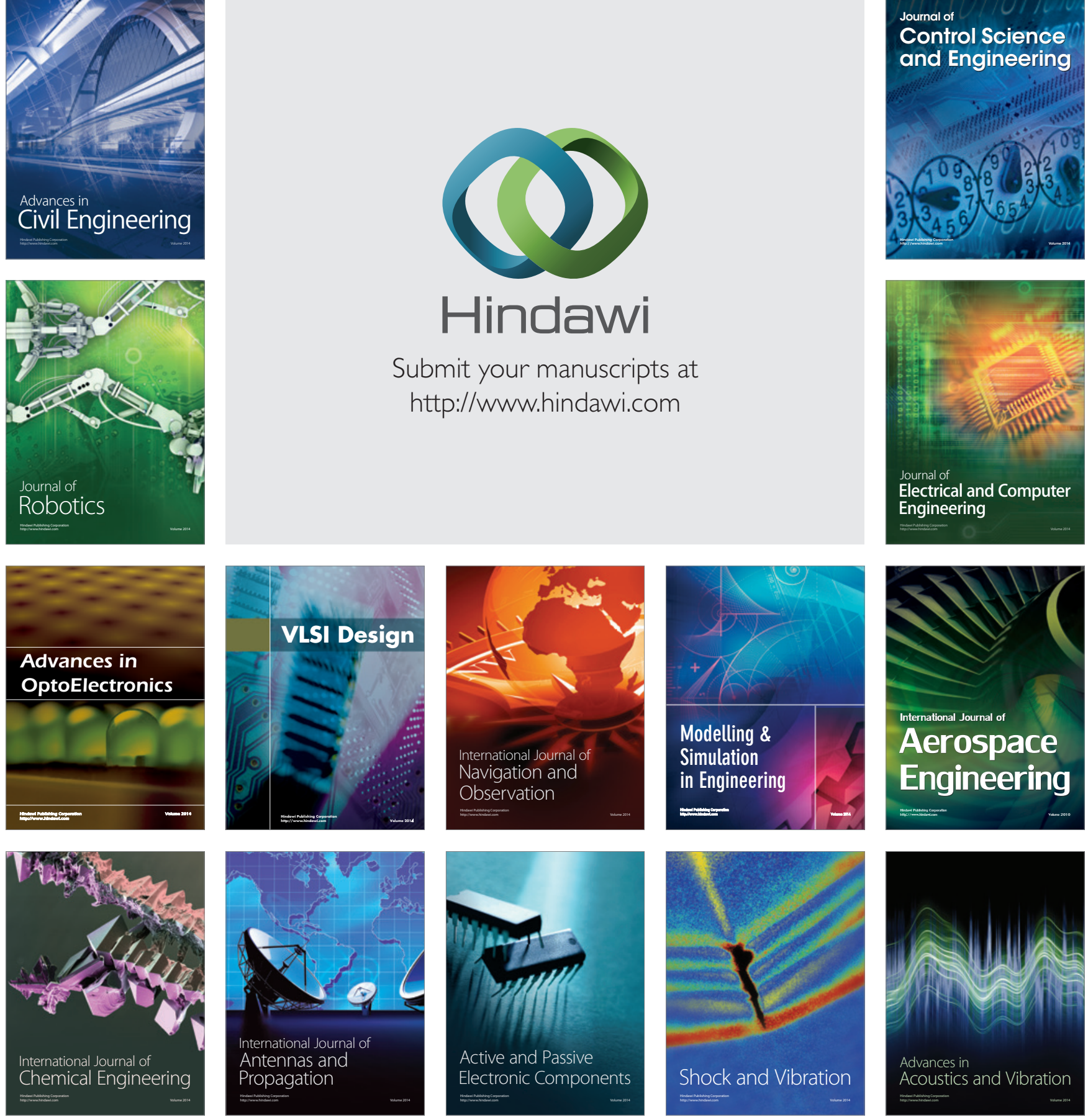